\title{
Differential Protease Expression by Cutaneous Squamous and Basal Cell Carcinomas
}

\author{
André-Pascal Sappino," Dominique Belin," Joaquin Huarte, Suzanne Hirschel-Scholz," \\ Jean-Hilaire Saurat, ${ }^{*}$ and Jean-Dominique Vassalli \\ ${ }^{*}$ Division of Onco-Haematology, Institute of Histology and Embryology, ${ }^{\ddagger}$ Clinic of Dermatology, \\ Department of Pathology, University of Geneva Medical School, 1211 Geneva 4, Switzerland
}

\begin{abstract}
To assess the postulated role of plasminogen activation in tumor invasion, we have investigated the cellular sites of synthesis for urokinase-type (uPA) and tissue-type (tPA) plasminogen activators and their inhibitors (PAI-1 and PAI-2) in two human cutaneous neoplasia that differ in their metastatic potential. The combined use of zymography on tissue sections and in situ hybridization demonstrates that uPA is produced by malignant cells of squamous cell carcinomas (SCC) but not by basal cell carcinomas (BCC), whereas tPA is detected exclusively in nonmalignant dermal tissue. In addition, we show that SCC neoplastic cells simultaneously produce variable amounts of PAI-1, and that PAI-1 production correlates inversely with uPA enzymatic activity. These observations establish that invasive human malignant cells in vivo can activate plasminogen through uPA production during the early phases of tumor growth; they also demonstrate that the proteolytic activity of tumor cells can be modulated by the concomitant production of PAI-1. Because SCC have a higher invasive and metastatic potential than BCC, our findings lend further support to the involvement of plasminogen activation in malignant behavior. (J. Clin. Invest. 1991. 88:1073-1079.) Key words: in situ hybridization • metastasis • neoplasia • proteolysis • urokinase
\end{abstract}

\section{Introduction}

During the past decade, the picture has emerged that modulation of cell-extracellular matrix (ECM) interactions are required for cell migration and tissue invasion processes; such modulation may play a pivotal role in the development of cancer metastases (for review, see reference 1). In particular, neoplastic cells need to solubilize and penetrate the ECM to invade adjacent nonmalignant tissues $(2,3)$. Tumor cells are

Address correspondence and reprint requests to A.-P. Sappino, M.D., Division of Onco-Haematology, Centre Médical Universitaire, 1 rue Michel-Servet, 1211 Geneva 4, Switzerland.

Received for publication 6 March 1991 and in revised form 20 May 1991.

1. Abbreviations used in this paper: $\mathrm{BCC}$, basal cell carcinoma; ECM extracellular matrix; EGF, epidermal growth factor; PA, plasminogen activator; PAI-1, plasminogen activator inhibitor type 1; PAI-2, plasminogen activator inhibitor type 2; SCC, squamous cell carcinoma; TGF $\alpha$, transforming growth factor $\alpha$; tPA, tissue-type plasminogen activator; uPA, urokinase-type plasminogen activator.

J. Clin. Invest.

(c) The American Society for Clinical Investigation, Inc.

0021-9738/91/10/1073/07 \$2.00

Volume 88, October 1991, 1073-1079 known to produce and release a variety of degradative enzymes, and correlation between proteolytic enzyme production and metastatic potential have been documented in animal and human tumors $(4,5)$. Plasminogen activators (PAs) are serine proteases that convert plasminogen, a widely distributed zymogen, into plasmin, a neutral protease of broad specificity which is capable of degrading directly or indirectly most components of the ECM (for reviews, see references 3 and 6). Two types of PAs have been identified in mammals, urokinase-type (uPA) and tissue-type (tPA) plasminogen activators. uPA is known to be expressed by physiologically invasive cell types (7, 8); it has been proposed that the enzyme could participate in tumor invasion and metastasis (for review, see reference 3); indeed, high amounts of uPA are frequently associated with epithelial tumors and, in some instances, invasive and metastasizing properties have been shown to parallel the levels of enzyme production (9-12). However, the contribution of uPA to malignant invasive and metastatic phenotypes of human tumors remains based on indirect evidence.

To assess the participation of plasminogen activation during the early phases of tumor growth, we analyzed, by the combined use of histological zymography and in situ hybridization, cutaneous squamous (SCC) and basal cell carcinomas (BCC). Our observations establish that SCC cells, which have substantial metastatic potential (13), produce uPA, whereas BCC cells, which rarely metastasize, do not produce the enzyme, thus lending further support to the notion that plasmin-mediated proteolysis might provide tumor cells with efficient means to invade nonmalignant tissues.

\section{Methods}

Tissue sampling and histological assessment. Tumors were prospectively collected immediately after surgical removal and cut in two parts. One-half was frozen down in precooled methylbutane and stored at $-70^{\circ} \mathrm{C}$. The other half was fixed in $10 \%$ formalin and paraffin-embedded for histological examination.

According to standard histological criteria, 20 tumors were classified as BCC. 12 BCC were subtyped as nodular BCC, three as adenoid, and five were considered as fibrosing BCC. 10 tumors were classified as SCC. Three specimens were diagnosed as actinic keratosis without evidence of carcinoma.

Enzymatic analyses. Zymographies were performed on 10- $\mu \mathrm{m}$ cryostat tissue sections as previously described (14). Control experiments were carried out with overlay mixtures from which plasminogen was omitted; no proteolytic zones were observed in the absence of plasminogen, demonstrating that the lytic activities were due to PAs. To distinguish uPA from tPA, amiloride, a specific inhibitor of uPA-catalytic activity (15), was added to the substrate. As previously shown (14), in the presence of $1 \mathrm{mM}$ amiloride, uPA activity is completely suppressed, whereas tPA activity is only slightly decreased. Photographs were taken after 4-6 $\mathrm{h}$ incubation at $37^{\circ} \mathrm{C}$, using dark-field illumination.

Plasmid constructions, in vitro transcriptions, and Northern blot analysis. The uPA antisense probe was prepared from pSP64-hUK, 
containing the 610-bp Eco RI-Pst I fragment isolated from pHUK (16); the uPA sense probe was prepared from pSP65-hUK containing the 610-bp Pst I-Eco RI isolated from pHUK; the tPA probe was prepared from pSP65-hTA, containing the 614-bp Bgl II-Eco RI fragment isolated from pW349F (17); the PAI-1 probe was prepared from pSP64-hPAI-1 containing the 1.4-Kbp Eco RI-Bgl II fragment isolated from pPAI1-C1 (18); the PAI-2 probe was prepared from pDB4707 containing the 794 bp Eco RI-Xba I fragment of the human PAI-2 clone J.7 (19). Linearized plasmids were transcribed in vitro in the presence of $12.5 \mu \mathrm{M}$ of $\alpha^{32} \mathrm{P}$-labeled UTP ( $400 \mathrm{Ci} / \mathrm{mmol}$; Amersham International, Amersham, UK) or $30 \mu \mathrm{M}^{3} \mathrm{H}$-labeled UTP and $30 \mu \mathrm{M}$ ${ }^{3} \mathrm{H}$-labeled CTP $(40$ and $20 \mathrm{Ci} / \mathrm{mmol}$, respectively; Amersham International). ${ }^{3} \mathrm{H}$-labeled probes were reduced to an average size of 50-100 nt by mild alkaline hydrolysis as previously described (8).

Total RNA extractions from frozen skin specimens and Northern blot analysis were performed as described elsewhere (11).

In situ hybridizations. In situ hybridizations were carried out on $5-\mu \mathrm{m}$ cryostat tissue sections as previously described $(8,14)$. Sections hybridized to ${ }^{32} \mathrm{P}$-labeled probes were directly exposed to $\mathrm{x}$-ray films (SB5; Eastman Kodak Co., Rochester, NY) between intensifying screens and the films developed after $3 \mathrm{~d}$ exposure at room temperature, whereas sections hybridized to ${ }^{3} \mathrm{H}$-labeled probes were dipped in NTB-2 emulsion (Eastman Kodak Co.) diluted 1:1 in deionized water, exposed for 3-12 wk, developed in Kodak D-19 developer, fixed in $30 \% \mathrm{Na}$ thiosulfate, and counterstained in methylene blue.

Controls for specificity were performed as previously described (8, 14) and included the use of sense RNA probes. Photographs were taken with a conventional camera (Canon), using PAN-F Ilford black and white film. Microphotographs were taken with a Zeiss photomicroscope, equipped with an immersion dark-field condensor, using Kodak Ektachrome 50 color film.

\section{Results}

Squamous cell carcinomas. Histological zymographies performed on cryostat tissue sections of SCC displayed circumscribed zones of plasminogen-dependent caseinolysis. Both PAs can be revealed by this approach: activity inhibited by the addition of amiloride to the substrate corresponds to uPA, whereas activity which is minimally inhibited by amiloride corresponds to tPA $(14,15)$. In each of the 10 SCC specimens analyzed, we observed both enzymes: amiloride suppressed the zones of caseinolysis found exclusively over tumor cells (Figs. 1 and 2) indicating the presence of UPA; other areas of PA activity, only slightly inhibited by the addition of amiloride, were observed in the nonmalignant dermal tissues surrounding carcinomas (Fig. 2); this amiloride-resistant PA activity was abolished by the addition of anti-tPA antibodies to the substrate and immunohistochemistry revealed tPA immunoreactivity in endothelial cells lining dermal vessels (not shown).

These findings indicate that SCC express UPA, whereas adjacent nonmalignant dermal tissues express tPA. In contrast to SCC, three specimens of actinic keratosis did not show amiloride-sensitive caseinolytic zones, suggesting that this type of lesion is not associated with uPA expression (Table I). Though all 10 SCC displayed uPA activity, a quantitative heterogeneity was noted by the variation of incubation times necessary to visualize tumor-associated caseinolysis and by the variable size of these caseinolytic zones (compare Figs. 1 and 2).

The presence of mRNA for UPA and tPA in the tumor specimens was first analyzed by Northern blot hybridizations. As expected from the histological zymograms, both mRNAs were detected in SCC specimens (see Fig. 3, lane 2 for one representative sample). To determine the regional localization

of UPA mRNA, we next hybridized tissue sections to a ${ }^{32} \mathrm{P}$-labeled cRNA probe and evaluated them by film autoradiography. The distribution of UPA mRNA colocalized with the distribution of uPA enzymatic activity: the 10 SCC samples showed a positive uPA mRNA signal which was restricted to the tumor (Figs. 1, 2, and 4; Table I). The intensity of labeling varied between tumors and, in addition, it did not correlate precisely with the amount of enzymatic activity as assessed by histological zymographies: some tumors contained abundant uPA mRNA, with only low levels of enzymatic activity (Fig. 2), whereas others displayed a similarly intense uPA mRNA signal with abundant enzymatic activity (Fig. 1). No uPA mRNA was detected in the three specimens of actinic keratosis (Table I). Though as mentioned above, tPA is present in nonmalignant dermal tissue, we were not able to localize the cellular sites of tPA mRNA accumulation by in situ hybridizations; however, Northern blot analysis of total RNAs extracted from enzymatically-separated normal epidermal and dermal tissues displayed

\section{HISTOLOGICAL ZYMOGRAM $\mathrm{UPA}+\mathrm{tPA}$}

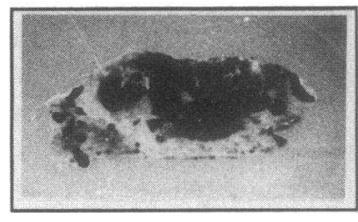

IN SITU HYBRIDIZATION UPA MRNA

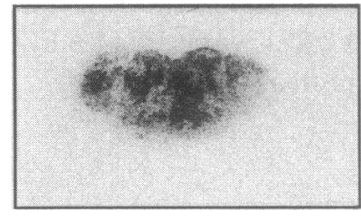

IN SITU HYBRIDIZATION PAI-1 mRNA



Figure 1. Visualization of PA activities and mRNAs on tissue sections of a squamous cell carcinoma. Histological zymograms show amiloride-sensitive PA enzymatic activity on tumoral tissue that corresponds to uPA, whereas minimal enzymatic activity, which is only slightly affected by amiloride, is detectable outside tumoral tissue and corresponds to tPA. In addition, a small zone of amiloride-sensitive activity is visible on the lower left of the sections shown in the top panels; this zone corresponds to foci of neoplastic cells that were not present in the sections used for histology and mRNA localizations. An accumulation of uPA mRNA is observed in tumoral tissue, whereas no significant signal is observed with the PAI-1 cRNA probe. Hybridization to the PAI-2 cRNA probe reveals a faint signal localized in the epidermis. Dotted line indicates the boundary of tumoral tissue. Photographs of zymograms were taken after 2-h (uPA + tPA) and 4-h (t-PA) incubations at $37^{\circ} \mathrm{C}$. Photographs of hybridizations were taken after $72 \mathrm{~h}$ exposure at room temperature (magnification, 2.5). 


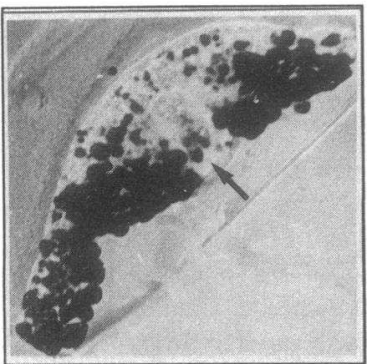

IN SITU HYBRIDIZATION UPA MRNA

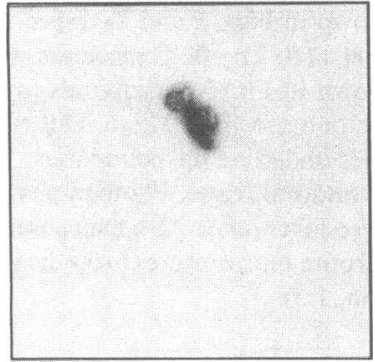

IN SITU HYBRIDIZATION PAI-1 mRNA

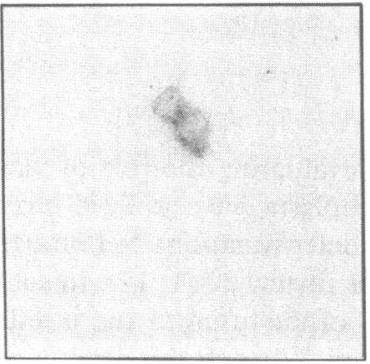

HISTOLOGICAL ZYMOGRAM tPA

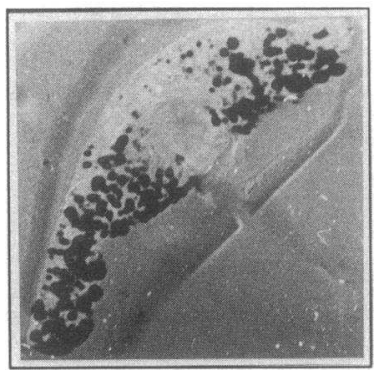

HISTOLOGICAL STAINING $H \& E$

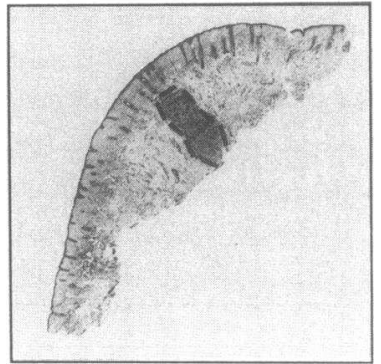

IN SITU HYBRIDIZATION Control

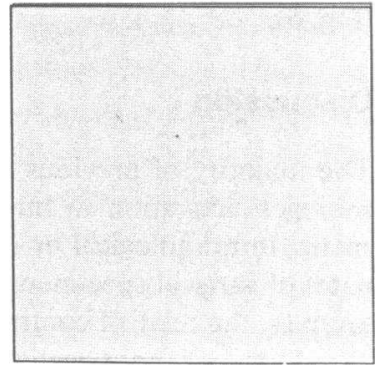

Figure 2. Visualization of PA activities and mRNAs on tissue sections of a squamous cell carcinoma. Histological zymograms show amiloride-resistant PA enzymatic activity (tPA) in dermal nontumoral tissues, whereas circumscribed foci of amiloride-suppressed PA enzymatic activity (UPA) are visible on the tumoral tissue (arrow). UPA and PAI-1 mRNAs are detected in tumoral tissue. Control hybridization was performed with the uPA sense probe. Dotted line indicates the boundary of tumoral tissue. Photographs of zymograms were taken after $2 \mathrm{~h}$ (uPA + tPA) and $4 \mathrm{~h}$ (tPA) incubations at $37^{\circ} \mathrm{C}$. Photographs of hybridizations were taken after $72 \mathrm{~h}$ exposure at room temperature (magnification, 1.5).

detectable levels of tPA mRNA in the dermis but not in the epidermis (not shown).

To identify the sites of uPA synthesis at the cellular level, we then hybridized adjacent tissue sections to a ${ }^{3} \mathrm{H}$-labeled cRNA probe and assayed them by emulsion autoradiography. These hybridizations confirmed the findings obtained with the ${ }^{32} \mathrm{P}$-labeled probe: uPA mRNA was found in neoplastic cells (Fig. 5, $A-C$ ). Though we observed intra- and intertumoral heterogeneity in the labeling, the most heavily labeled cells were consistantly found in tumoral zones immediately adjacent to the bordering normal dermis, whereas morphologically identifiable foci of inflammatory cells were devoid of specific signal (Fig. $5 \mathrm{C}$ ). There was no apparent correlation between

Table I. Production of PAs According to the Histological Type of Lesion

\begin{tabular}{lccc}
\hline \multicolumn{1}{c}{ Histology } & $\begin{array}{c}\text { uPA } \\
\text { activity* }\end{array}$ & $\begin{array}{c}\text { uPA } \\
\text { mRNA }^{*}\end{array}$ & $\begin{array}{c}\text { tPA } \\
\text { activity }\end{array}$ \\
\hline Squamous cell carcinomas & $10 / 10$ & $10 / 10$ & $0 / 10$ \\
Basal cell carcinomas & $0 / 20$ & $0 / 20$ & $0 / 20$ \\
Actinic keratosis & $0 / 3$ & $0 / 3$ & $0 / 3$
\end{tabular}

Number of positive specimens/number of specimens analyzed. * As assessed by amiloride-sensitive caseinolysis over lesional tissue on histological zymograms. ${ }^{*}$ As assessed by in situ hybridizations of ${ }^{32} \mathrm{P}$ and ${ }^{3} \mathrm{H}$-labeled cRNA probes to cryostat tissue sections. ${ }^{8}$ As assessed by amiloride-resistant caseinolysis over lesional tissue on histological zymograms.

the amount of inflammatory cells in and around tumoral tissues, as assessed by histological evaluation, and the number of malignant cells expressing uPA mRNA.

To clarify the discrepancies noticed between uPA enzymatic activity and UPA mRNA abundance, we explored corresponding tissues for the presence of specific PA inhibitors and their mRNAs. By Northern blot analysis, we detected PAI-1 mRNA in the total RNA extracted from some SCC specimens (Fig. 3). PAI-2 mRNA was detected in a single SCC specimen, that was also found to express PAI-1 mRNA. Tissue sections were then hybridized to ${ }^{32} \mathrm{P}$-labeled cRNA probes for PAI-1 and PAI-2. Four of 10 SCC displayed abundant PAI-1 mRNA, which appeared confined to the tumors (Fig. 2). Hybridizations to a ${ }^{3} \mathrm{H}$-labeled probe confirmed that numerous neoplastic cells in these four tumors contained PAI-1 mRNA (Fig. 5, $D$ and $E$ ).

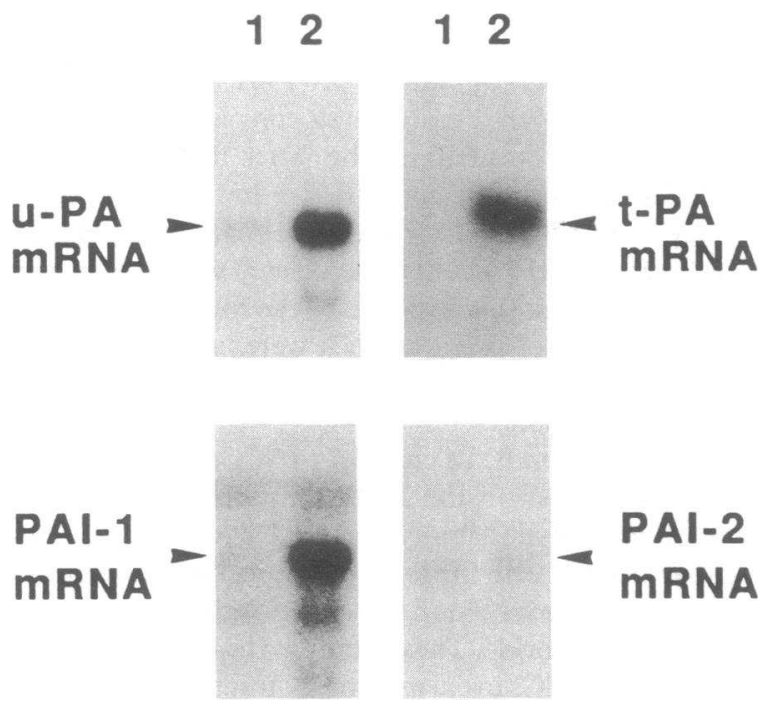

Figure 3. Northern blot analysis of uPA, tPA, PAI-1, and PAI-2 mRNAs in basal (1) and squamous cell (2) carcinomas. $10 \mu \mathrm{g}$ of total RNA extracted from the specimens shown in Fig. 3 and 2, respectively, were analyzed using corresponding cRNA probes. The absence of detectable tPA mRNA in the BCC specimen (lane 1 ) is due to the fact that very little dermal tissue was available for extraction when compared to the SCC specimen (lane 2). The membranes were exposed together for $72 \mathrm{~h}$ at $-80^{\circ} \mathrm{C}$ between intensifying screens. Even loading and the integrity of RNAs were verified by staining membranes after transfer with methylene blue. 


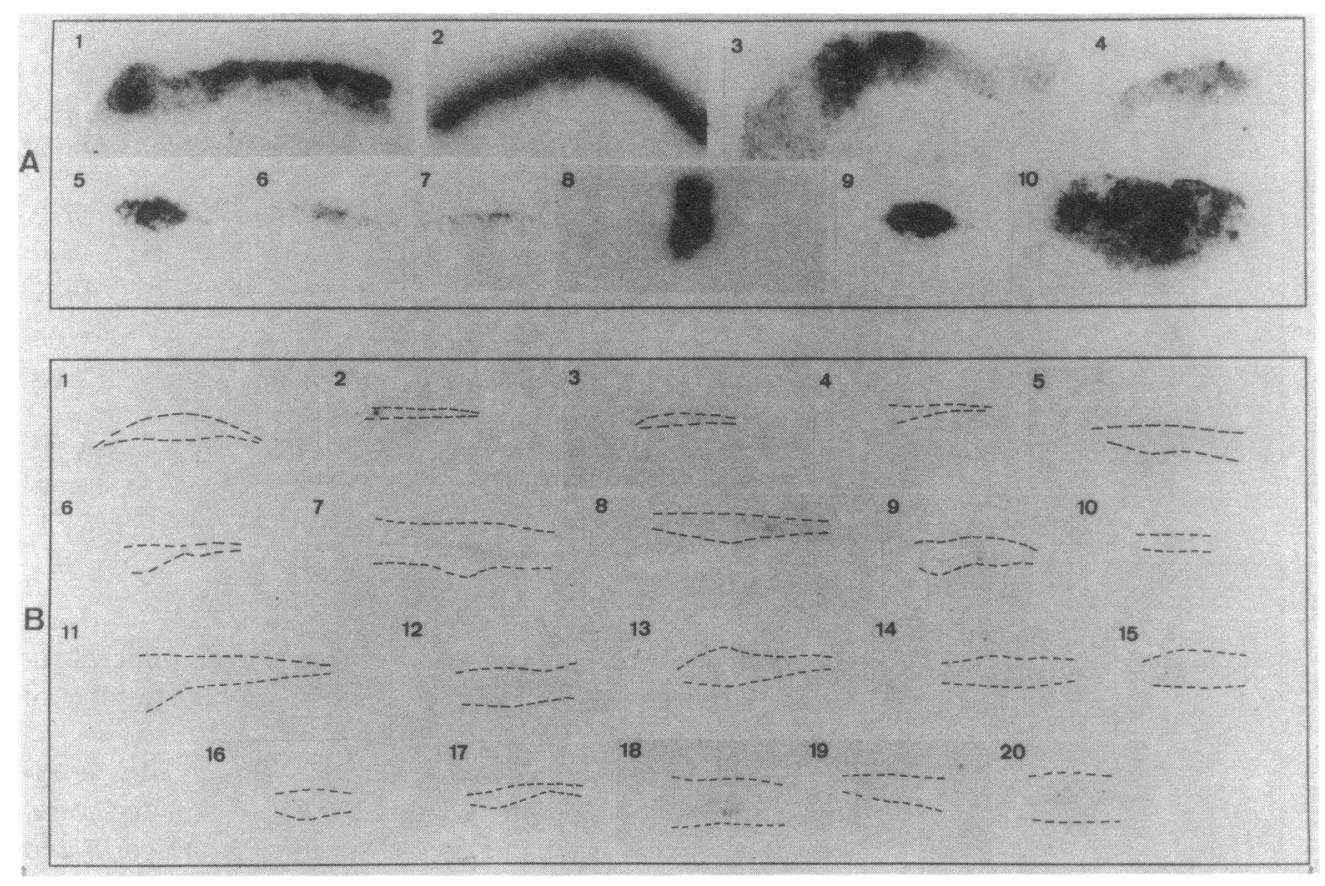

Figure 4. Detection of uPAmRNA in tissue sections of SCC $(A)$ and $\mathrm{BCC}(B)$ by in situ hybridizations to a ${ }^{32} \mathrm{P}$-labeled cRNA probe. Significant, although variable, amounts of $\mathrm{UPA}$ mRNA are observed in all SCC. $(A)$ The SCC specimens shown in 10 and 8 correspond to those shown in Figs. 1 and 2, respectively. $(B)$ The BCC specimen shown in Fig. 5 corresponds to the one shown in Fig. 6. Dotted lines underline the boundaries of tumoral tissue. Photographs were taken after $72 \mathrm{~h}$ exposition at room temperature (magnification, 1.5).
A few malignant cells containing PAI- 1 mRNA were observed in the remaining six specimens of SCC. As expected from Northern blot analysis, only 1 SCC was found to contain, together with PAI-1 mRNA, significant levels of PAI-2 mRNA, which was localized to tumor cells (not shown). PAI-2 mRNA was also found in the normal epidermal cells of all specimens analyzed (Figs. 1 and 6). In addition, we performed histochemical analysis to reveal the presence of inhibitors of uPA: the zymographic procedure was carried out in the presence of exogenous uPA in the substrate (not shown). These experiments showed that the tumors containing PAI- 1 mRNA produced an inhibitor of uPA-catalyzed caseinolysis, precisely in the areas of PAI-1 mRNA accumulation. The latter findings indicate that tumor cells can produce active PAI-1 and that the expression of high levels of inhibitor by a subset of tumors may account for the decreased PA activity associated with certain SCC tumors. In accord with this hypothesis, the four SCC containing the highest levels of PAI-1 mRNA were precisely those in which the discrepancy between uPA mRNA and enzyme activity was most remarkable.

Basal cell carcinomas. In contrast to SCC, histological zymographies performed on the $20 \mathrm{BCC}$ specimens revealed a single type of caseinolytic activity (Fig. 6). This enzymatic activity was not associated with the tumoral tissue, but was localized to the dermal layers, over blood vessels; enzymatic activity was not inhibited by amiloride. These findings indicate that uPA is not detectable in $\mathrm{BCC}$, even in tumors infiltrating the deep layers of the dermis, and that TPA, like in SCC specimens, is predominantly associated with nonmalignant tissues (Table I).

Northern blot as well as macroscopic and microscopic localization studies of UPA mRNA confirmed that BCC cells did not produce uPA. Indeed, no positive signal was observed with either ${ }^{32} \mathrm{P}$-labeled (Figs. 3, 4, and 6; Table I) or ${ }^{3} \mathrm{H}$-labeled uPA cRNA probes (not shown).

Similarly, no positive labeling was observed either with ${ }^{32} \mathrm{P}$ (Figs. 3 and 6) or ${ }^{3} \mathrm{H}$-labeled probes for PAI-1 mRNA (not shown), indicating that BCC also differ from SCC in their abil- ity to synthesize inhibitors. Finally, as noticed in SCC specimens, PAI-2 mRNA was present in the normal epidermis (Fig. 6).

\section{Discussion}

The majority of previous studies evaluating the role of plasminogen activation in human neoplasia have utilized enzymatic, immunological or mRNA determinations of homogenates of surgical specimens (see for review $3,11,12$ ). In such samples, the relative contributions of the tumoral and nontumoral tissues cannot be distinguished. Whereas this distinction is provided by immunohistochemical localizations, estimations based solely on antigen recognition might provide erroneous information. For instance, uPA is a secreted protease that can bind to specific cell surface receptors $(20,21)$ and both PAs can be inhibited by specific antiproteases (22-25); therefore, protein localizations might not identify the cellular sites of synthesis for PAs and their inhibitors, or the regions where the enzymatic system may be most active. To evaluate the postulated involvement of the PA-plasmin system in tumor invasion, we localized UPA and PAI mRNAs and determined the catalytic activity of PAs in histological tissue sections from a series of cutaneous epithelial tumors. Our observations show that such an approach may provide novel information about the PA system of tumoral tissues.

In vitro and in vivo studies have shown that nonmalignant cutaneous tissues can produce uPA, in particular during processes involving cell migration and tissue remodeling (26-28). The present study demonstrates that carcinoma cells of a defined histological type synthesize uPA in vivo. We localized uPA mRNA exclusively in a subset of SCC neoplastic cells and found that the most heavily labeled cells were located predominantly near the border with nonmalignant tissues. Histological zymographies revealed that uPA catalytic activity was restricted to regions of the tissues in which uPA mRNA was detected. Cells containing uPA mRNA were present in all SCC 

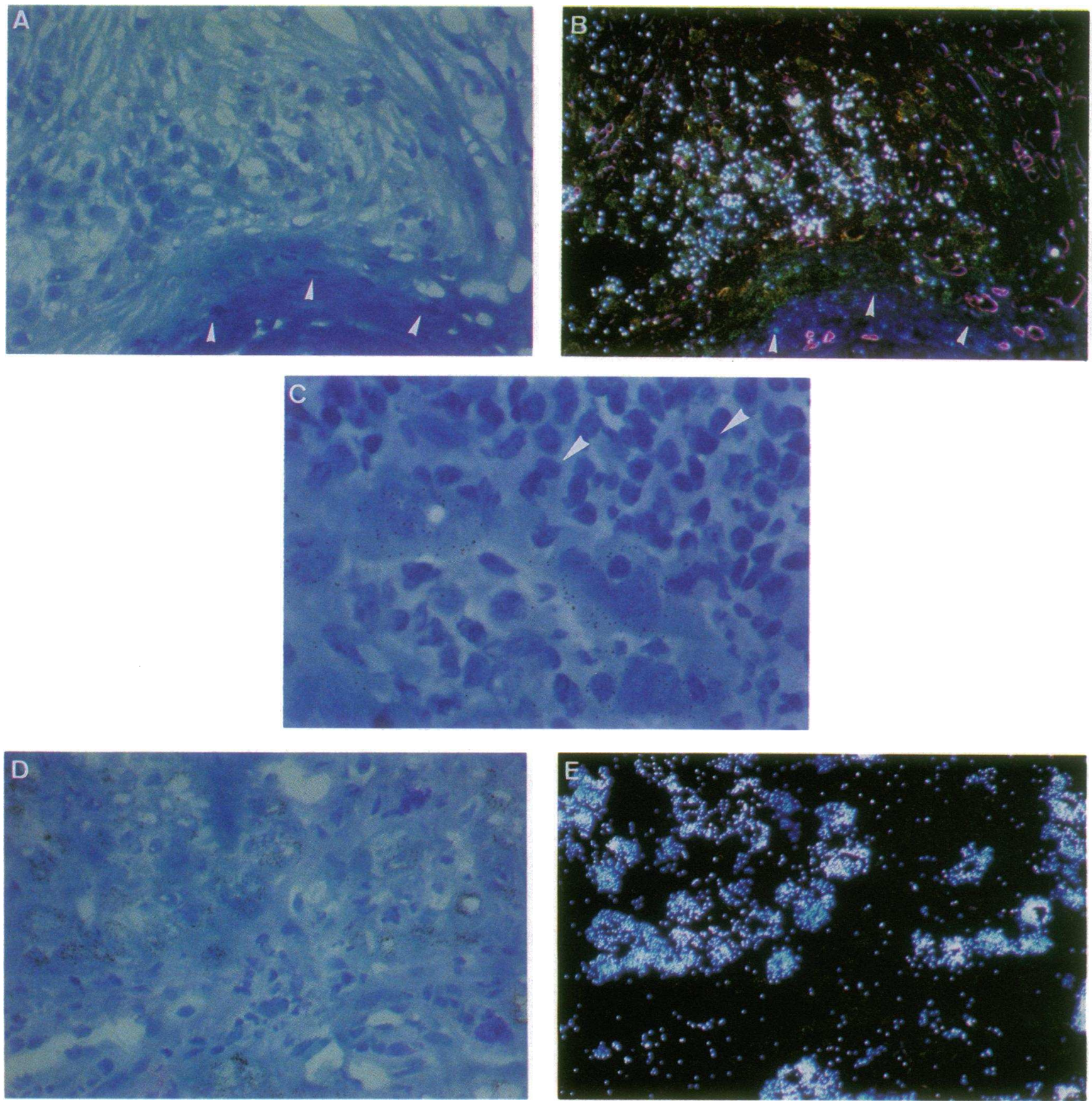

Figure 5. Localization of uPA $(A-C)$ and PAI-1 mRNA $(D$ and $E)$ by in situ hybridizations of ${ }^{3} \mathrm{H}-$ labeled cRNA probes to cryostat tissue sections of two squamous cell carcinomas. $A, C$, and $D$ are light-field micrographs. $B$ and $E$ are the corresponding dark-field micrographs of those shown in $A$ and $D$, respectively. ( $A$ and $B$ ) High magnification of a tissue section from the specimen shown in Fig. 1. Foci of tumor cells localized in the vicinity of nonmalignant tissues (arrowheads) contain uPA mRNA. $(C)$ High magnification of a tissue section from the specimen shown in Fig. 2. Isolated tumor cells contain uPA mRNA, while adjacent inflammatory cells are unlabeled (arrowheads). $(D$ and $E)$ High magnification of a tissue section from the specimen shown in Fig. 2. Numerous tumor cells contain high amounts of PAI-1 mRNA. Slides were exposed for 12 wk (magnifications, $A, B, D$, and $E, 1,200 ; \mathrm{C}, 3,000$ ).

specimens, although their proportion varied between tumors. In addition, for certain tumors, we observed apparent discrepancies between the amount of UPA mRNA assessed by in situ hybridizations and the extent of catalytic activity visualized by histological zymographies. When corresponding tissue sections were analyzed for the expression of specific inhibitors, we found that all SCC contained variable amounts of cells expressing PAI-1 mRNA. In four of 10 SCC numerous malignant cells displayed abundant levels of PAI-1 mRNA. Relatively little enzymatic activity was expressed by these four tumors which 


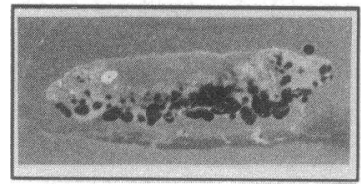

IN SITU HYBRIDIZATION UPA MRNA

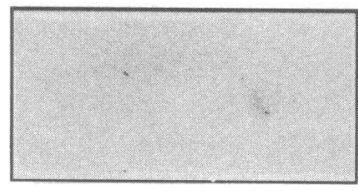

IN SITU HYBRIDIZATION PAI-1 mRNA

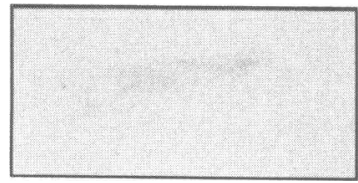

Figure 6. Visualization of PA activities and mRNAs on tissue sections of a basal cell carcinoma. Histological zymograms show the absence of PA activity in the tumoral tissue. tPA activity, which is somewhat decreased in the presence of amiloride (see Methods), is present only in dermal tissues (14). No uPA or PAI-1 mRNA is observed, whereas PAI-2 mRNA is detected in the epidermis. Dotted line indicates the boundary of tumoral tissue. Photographs of zymograms were taken after 2-h (uPA + tPA) and 4-h (tPA) incubations at $37^{\circ} \mathrm{C}$. Photographs of hybridizations were taken after $72 \mathrm{~h}$ exposure at room temperature (magnification, 1.5).

differed clearly from the remaining SCC in which only occasional cells containing PAI- 1 mRNA were detected. By forming essentially irreversible complexes with PAs, secreted PAIs are considered to limit the extent of PA-catalyzed extracellular proteolysis (for review see reference 29). Numerous tumor cell lines and total tumor extracts are known to contain PAI-1 and/ or PAI-2 $(30,31)$, and experimental studies have shown that both PAIs can interfere with tumor cell-mediated degradation of $\operatorname{ECM}(32,33)$. Our results suggest that PAI-1 produced by the tumor cells themselves can decrease, to a varying degree, the activity of the uPA synthesized by a subset of the malignant cells. However, we have presently no evidence suggesting that these four tumors differed clinically from the six SCC that did not express PAI- 1 mRNA.

Our observations demonstrate that the production of UPA is a feature of SCC, a tumor capable of metastasizing, whereas nonmetastasizing BCC do not contain UPA or UPA mRNA. Numerous enzymatic and radioimmunometric assays performed on human tissues have revealed increased amounts of uPA in tumors, when compared with their nonneoplastic counterparts (for review see reference 3). However, a correlation between enhanced uPA expression and metastasis has been observed in only a minority of studies $(11,12)$, whereas the majority of data reported in human tumors failed to demonstrate a significant correlation between PA activity and the met- astatic phenotype (for review see reference 3 ). These apparent discrepancies could be due to the limitations inherent to nonhistological assays, as discussed above, and/or to sampling procedures. Indeed, experimental models suggest that the contribution of proteolytic mechanisms to tissue invasion and metastasis formation is particularly critical during the initial phases of tumor invasion (34-37). In contrast to most studies that have explored the production of PAs in tumoral tissues at relatively advanced stages of evolution, our analysis was directed at the exploration of small tumors, which are usually excised before dissemination has occurred. Our findings document the participation of the PA-plasmin system in localized primary tumors and suggest that its evaluation in early neoplastic lesions may be of diagnostic value in assessing their metastatic potential.

There is presently no available molecular marker that may discriminate SCC from $\mathrm{BCC}$, and the histogenetical origin of these two types of epithelial tumors is still debated (13). The production of uPA may represent a differentiation feature of SCC as opposed to BCC, or alternatively reflect response of SCC cells to yet undefined external stimuli. In many normal tissues, as well as in a number of tumor-derived cell lines, uPA and PAIs production are under tight control of hormones and growth factors (for reviews see references 3 and 29). The clear difference observed in our study between two types of epidermal carcinomas with respect to uPA production suggests a difference in the presence of or response to putative growth factors, such as, for example, epidermal growth factor (EGF). Indeed, EGF has been shown to induce uPA production in normal (38) as well as in transformed keratinocytes $(39,40)$; furthermore, TGF $\alpha$ has been found in some skin tumors (41) and proliferating keratinocytes are known to express EGF/ TGF $\alpha$ receptors (for review see reference 42). These observations raise the possibility that uPA production may result from alterations in growth factor signaling systems. Inflammatory cells could be the source of growth factors, although our findings failed to show a correlation between the extent of inflammatory infiltrates and the production of UPA by tumor cells. Finally, it is of interest to note that plasmin may exert a wider spectrum of activities than previously suspected and that the role of this enzyme in neoplasia may not be restricted to the degradation of ECM constituents; for example, plasmin-mediated proteolysis could activate latent forms of growth factors which are known to influence the growth and differentiation of neoplastic cells (43).

\section{Acknowledgments}

We thank Dr. I. Masouyé for helpful discussions, D. Ducrest, M. Khoshbeen, and M.-T. Morand for technical assistance, and J.-C. Rumbeli for photographic work.

This work was supported by the Swiss National Science Foundation and by the Geneva League Against Cancer.

\section{References}

1. Alexander, C. M., and A. Z. Werb. 1989. Proteinases and extracellular matrix remodeling. Curr. Opin. Cell Biol. 1:974-982.

2. Goldfarb, R. H., and L. A. Liotta. 1986. Proteolytic enzymes in cancer invasion and metastasis. Semin. Thromb. Hemostasis. 12:294-307.

3. Danø, K., P. A. Andreasen, J. Grøndhal-Hansen, P. Kristensen, L. S. Nielsen, and L. Skriver. 1985. Plasminogen activators, tissue degradation, and cancer. Adv. Cancer Res. 44:139-266.

4. Liotta, L. A., K. Tryggvason, S. Garbisa, I. Hart, C. M. Foltz, and S. Shafie. 
1980. Metastatic potential correlates with enzymatic degradation of basement membrane collagen. Nature (Lond.). 284:67-68.

5. Spyratos F., T. Maudelonde, J. P. Brouillet, M. Brunet, A. Defrenne, C Andrieu, K. Hacene, A. Desplaces, J. Rouëssé, and H. Rochefort. 1989. Cathepsin D: an important marker predicting metastasis in primary breast cancer. Lancet. 1115-1118.

6. Reich, E. 1978. Activation of plasminogen: a general mechanism for producing localized extracellular proteolysis. In Molecular Basis of Biological Degradative Processes. R. D. Berlin, H. Hermann, I. H. Lepow, and J. M. Tanzer, editors. Academic Press, Inc., New York. 155-169.

7. Strickland, S., E. Reich, and M. I. Sherman. 1976. Plasminogen activator in early embryogenesis: enzyme production by trophoblast and parietal endoderm Cell. 15:393-403.

8. Sappino, A.-P., J. Huarte, D. Belin, and J.-D. Vassalli. 1989. Plasminogen activators in tissue remodeling and invasion: mRNA localization in mouse ovaries and implanting embryos. J. Cell Biol. 109:2471-2479.

9. Wang, B. S., G. A. McLaughling, and J. P. Richie. 1980. Correlation of the production of plasminogen activator with tumor metastasis in B16 melanoma cell lines. Cancer Res. 40:228-232.

10. Yu, H., and R. M. Schultz. 1990. Relationship between secreted urokinase plasminogen activator activity and metastatic potential in murine B16 cells transfected with human urokinase sense and antisense genes. Cancer Res. 50:76237633.

11. Sappino, A.-P., N. Busso, D. Belin, and J.-D. Vassalli. 1987. Increase of urokinase-type plasminogen activator gene expression in human lung and breast carcinomas. Cancer Res. 47:4043-4046.

12. Duffy, M. J., D. Reilly, C. O'Sullivan, N. O'Higgins, J. J. Fenelly, and P. Andreasen. 1990. Urokinase-plasminogen activator, a new and independent prognostic marker in breast cancer. Cancer Res. 50:6827-6829.

13. Lever, W. F., and G. Schaumburg-Lever. 1983. Histopathology of the Skin. J. B. Lippincott, Philadelphia, PA. 498-506, 562-575.

14. Sappino, A.-P., J. Huarte, J.-D. Vassalli, and D. Belin. 1991. Sites of synthesis of urokinase and tissue-type plasminogen activator in the murine kidney. J. Clin. Invest. 87:962-970.

15. Vassalli, J.-D., and D. Belin. 1987. Amiloride selectively inhibits the urokinase-type plasminogen activator. FEBS (Fed. Eur. Biochem. Soc.) Lett. 214:187191.

16. Verde, P., M. P. Stoppelli, M. Galleffi, P. Di Nocera, and F. Blasi. 1984 Identification and primary sequence of an unspliced human urokinase poly (A) + RNA. Proc. Natl. Acad. Sci. USA. 81:4727-4731.

17. Fisher, R., E. K. Waller, G. Grossi, D. Thompson, R. Tizard, and W. D. Schleuning. 1985. Isolation and characterization of the human tissue-type plasminogen activator structural gene including its $5^{\prime}$ flanking region. J. Biol. Chem. 260:11223-11230.

18. Andreasen, P. A., A. Riccio, K. G. Welinder, R. Douglas, R. Sartorio, L. S Nielson, C. Oppenheimer, F. Blasi, and K. Danø. 1986. Plasminogen activator inhibitor type-1: reactive center and amino-terminal heterogeneity determined by protein and cDNA sequencing. FEBS (Fed. Eur. Biochem. Soc.) Lett 209:213-218.

19. Belin, D., A. Wohlwend, W.-D. Schleuning, E. K. O. Kruithof, and J.-D. Vassalli. 1989. Facultative polypeptide translocation allows a single mRNA to encode the secreted and cytosolic forms of plasminogen activators inhibitor 2 . EMBO (Eur. Mol. Biol. Organ.) J. 8:3287-3294.

20. Vassalli, J.-D., D. Baccino, and D. Belin. 1985. A cellular binding site for the Mr 55,000 form of the human plasminogen activator urokinase. J. Cell Biol. 100:86-92.

21. Stoppelli, M. P., A. Corti, A. Soffientini, G. Cassani, F. Blasi, and R. K Assoian. 1985. Differentiation-enhanced binding of the amino-terminal fragment of human urokinase plasminogen activator to a specific receptor on U-937 monocytes. Proc. Natl. Acad. Sci. USA. 82:4939-4943.

22. Levin, E. G. 1983. Latent tissue plasminogen activator produced by human endothelial cells in culture: evidence for an enzyme-inhibitor complex. Proc. Natl. Acad. Sci. USA. 80:6804-6808.
23. Loskutoff, D. J., J. A. van Mourik, L. A. Erickson, and D. Lawrence. 1983. Detection of an unusually stable fibrinolytic inhibitor produced by bovine endothelial cells. Proc. Natl. Acad. Sci. USA. 80:2956-2960.

24. Lecander, I., and B. Ảstedt. 1986. Isolation of a new plasminogen activator inhibitor from pregnancy plasma. Br. J. Haematol. 62:221-228.

25. Baker, J. B., D. A. Low, R. L. Simmer, and D. D. Cunningham. 1980 Protease-nexin: a cellular component that links thrombin and plasminogen activator and mediates their binding to cells. Cell. 21:37-45.

26. Grøndahl-Hansen, J., E. Ralfkier, L. S. Nielsen, P. Kristensen, G. Frenz and K. Danø. 1987. Immunohistochemical localization of urokinase- and tissuetype plasminogen activators in psoriatic skin. J. Invest. Dermatol. 88:28-32.

27. Morioka, S., G. S. Lazarus, J. L. Baird, and P. Jensen. 1987. Migrating keratinocytes express urokinase-type plasminogen activator. J. Invest. Dermatol. 88:418-423.

28. Grøndahl-Hansen, J., L. R. Lund, E. Ralfkier, V. Ottevanger, and K Danø. 1988. Urokinase- and tissue-type plasminogen activators in keratinocytes during wound reepithelialization in vivo. J. Invest. Dermatol. 90:790-795.

29. Andreasen, P. A., B. Georg, L. R. Lund, A. Riccio, and S. N. Stacey. 1990. Plasminogen activator inhibitors: hormonally regulated serpins. Mol. Cell. Endocrinol. 68:1-19.

30. Cajot, J.-F., E. K. O. Kruithof, W.-D. Schleuning, B. Sordat, and F. Bachmann. 1986. Plasminogen activators, plasminogen activator inhibitors and procoagulant analyzed in twenty human tumor cell lines. Int. J. Cancer. 38:719-727.

31. Heidtmann, H. H., M. Hofmann, E. Jacob, C. Erbil, K. Havemann, and R. Schwartz-Albiez. 1989. Synthesis and secretion of plasminogen activators and plasminogen activator inhibitors in cell lines of different groups of human lung tumors. Cancer Res. 49:6960-6965.

32. Cajot, J.-F., J. Bamat, G. E. Bergonzelli, E. K. O. Kruithof, R. L. Medcalf, J. Testuz, and B. Sordat. 1990. Plasminogen-activator inhibitor type 1 is a potent natural inhibitor of extracellular matrix degradation by fibrosarcoma and colon carcinoma cells. Proc. Natl. Acad. Sci. USA. 87:6339-6343.

33. Baker, M. S., P. Bleakley, G. C. Woodrow, and W. F. Doe. 1990. Inhibition of cancer cell urokinase plasminogen activator by its specific inhibitor PAI-2 and subsequent effects on extracellular matrix degradation. Cancer Res. 50:4676-4684.

34. Ossowski, L., and E. Reich. 1983. Antibodies to plasminogen activator inhibit human tumor metastasis. Cell. 35:611-619.

35. Mignatti, P., E. Robbins, and D. B. Rifkin. 1986. Tumor invasion through the human amniotic membrane: requirement for a proteinase cascade. Cell. 47:487-498.

36. Ossowski, L. 1988. Plasminogen activator dependent pathways in the dissemination of human tumor cells in the chick embryo. Cell. 52:321-328.

37. Ossowski, L. 1988. In vivo invasion of modified chorioallantoic membrane by tumor cells: the role of cell surface-bound urokinase. J. Cell Biol. 107:2437-2445.

38. Grimaldi, G., P. Di Fiore, E. K. Locatelli, J. Falco, and F. Blasi. 1986 Modulation of urokinase plasminogen activator gene expression during the transition from quiescent to proliferative state in normal mouse cells. $E M B O$ (Eur Mol. Biol. Organ.) J. 5:855-861.

39. Stoppelli, M. P., P. Verde, G. Grimaldi, E. K. Locatelli, and F. Blasi. 1986 Increase in urokinase plasminogen activator mRNA synthesis in human carcinoma cells is a primary effect of the potent tumor promoter, phorbol myristate acetate. J. Cell Biol. 102:1235-1241.

40. Niedbala, M. J., and A. C. Sartorelli. 1989. Regulation by epidermal growth factor of human squamous cell carcinoma plasminogen activator-mediated proteolysis of extracellular matrix. Cancer Res. 49:3302-3309.

41. Gottlieb, A. B., C. K. Chang, D. N. Posnett, B. Fanelli, and J. P. Tam 1988. Detection of transforming growth factor $\alpha$ in normal, malignant, and hyperproliferative human keratinocytes. J. Exp. Med. 167:670-675.

42. King, L. E., R. E. Gates, C. M. Stoscheck, and L. B. Nanney. 1990. The EGF/TGF $\alpha$ receptor in skin. J. Invest. Dermatol. 94:164S-170S.

43. Sato, Y., and D. Rifkin. 1989. Inhibition of endothelial cell movement by pericytes and smooth muscle cells: activation of a latent transforming growth factor $\beta$-1-like molecule by plasmin during co-culture. J. Cell Biol. 109:309-315. 